\title{
El anti-don Juan de María de Zayas
}

\author{
María de Zayas' anti-don Juan
}

\author{
Marcella Trambaioli \\ Università del Piemonte Orientale
}

\section{RESUMEN}

Los críticos concuerdan en que María de Zayas escribe inspirada por la cólera que le provoca la condición femenina coetánea. Tanto en sus novelas como en la única comedia conservada, $L a$ traición en la amistad, Zayas censura con sutil ironía al tipo donjuanesco que se burla de las mujeres dejándolas sin honor, y lo hace entablando un complejo e ingenioso diálogo intertextual con El burlador de Sevilla. De forma especial, en la pieza lo hace a través de tres figuras: Liseo, que engaña a tres mujeres, Fenisa, un don Juan mujer aún más hiperbólico que Liseo, y don Juan, el menos donjuanesco de todos. En definitiva, crea un anti-don Juan parecido al que Ventura de la Vega realizará en el siglo XIX con El hombre de mundo, parodia del Tenorio de Zorrilla, pero con una clara intencionalidad ética: la de aleccionar a las mujeres de su época para que aprendan a esquivar a los hombres que abusan de ellas.

Palabras Clave: María de Zayas, La traición en la amistad, Novelas amorosas y ejemplares, Desengaños amorosos, El burlador de Sevilla, parodia, diálogo intertextual, crítica moral del hombre donjuanesco.

\section{ABSTRACT}

All critics agree on considering that María de Zayas writes inspired by the anger that she feels for the women condition. Both in her prose and in the only play we know, La traición en la amistad, Zayas censures with irony and wit the don-Juan type who deceives women leaving them without honour. She does it elaborating an intertextual relationship with El burlador de Sevilla. Specifically, in the play she uses three characters: Liseo, who deceives three women, Fenisa, who is a don-Juan female even more exaggerated than Liseo, and don Juan, the less donjuanesco of all. As a matter of fact, Zayas creates an anti-don Juan similar to the one that Ventura de la Vega will realize in the XIX century with his play El hombre de mundo, a parody of Zorrilla's Don Juan Tenorio; nevertheless it has a clear ethical purpose: to warn women of his age in order to avoid men's abuses.

Key words: María de Zayas, La traición en la amistad, Novelas amorosas y ejemplares, Desengaños amorosos, El burlador de Sevilla, parody, intertextuality, moral critics of the donJuan type. 
Los críticos concuerdan en destacar que María de Zayas escribe inspirada por la cólera que le provoca la condición femenina coetánea ${ }^{1}$. Sus tramas y personajes se salen de los derroteros consabidos de la novela corta, proponiendo soluciones inéditas al conflicto entre hombres y mujeres. Tanto las Novelas amorosas y ejemplares (Zayas, 2000) como los Desengaños amorosos (Zayas, 1993), aun con las notables diferencias que separan las dos colecciones, se enhebran alrededor de un tema fundamental: el del engaño y abusos de los hombres ${ }^{2}$. Casi sin excepciones los protagonistas de sus relatos son unos burladores seriales de mujeres, tipología masculina que, desde luego, halla en la figura de don Juan Tenorio su más acabada ejemplificación. También en la única comedia zayesca conocida, La traición en la amistad (Zayas, 1994), la condena del comportamiento donjuanesco resulta medular.

Ahora bien, en la época en que Zayas escribe sus obras El burlador de Sevilla es ya una pieza conocida, sea cual fuere su autor y sus avatares textuales $^{3}$. Recordemos que, aunque la editio princeps parece ser de 1627 (Cruickshank, 1981), los estudiosos consideran que la composición podría datarse en los años 1617-16194. Según Melloni, el análisis métrico de La traición en la amistad apuntaría a una fecha de redacción alrededor de 1610-1615 . Sin

${ }^{1}$ Cfr. Foa (1978: 129): «Zayas protesta con violencia de «todo el régimen social del amor, con sus tópicos de cortejamiento, tentación, engaño, deshonor, venganza, etcétera [que busca] mantener a las mujeres en una situación de inferioridad y desprecio»»; Díez Borque (1979: 74): «Es lógico que Zayas, coherente con su pensamiento, ataque virulentamente al hombre, responsable de tanta maldad. Con ello quebranta los límites de una literatura feminista para entrar en los de una literatura anti-hombre, sin tradición como la misógina y, prácticamente, sin antecedentes ni continuadores»; Riera y Cotoner (1987: 150): «En nuestra opinión, Zayas escribe, en verdad, movida por la cólera»; Alcalde (2005: 9): «la autora se predispone para la defensa de una determinada postura ideológica que toma como partido la reivindicación de la condición femenina».

${ }^{2}$ Cfr. Díez Borque (1979: 73): «La idea repetida, insistiré, es que el hombre engaña siempre y Zayas lo repite novela a novela».

${ }^{3}$ Con respecto a la autoría del primer don Juan, subscribo las siguientes palabras de Arellano (en Tirso 1997: 57): «La resistencia a despojar a Tirso (uno de los principales dramaturgos áureos) del Burlador (una de la principales comedias del Siglo de Oro) ha derivado a veces en disputas subjetivas y parcialidades apasionadas. Tampoco, a mi juicio, se ha llegado a conclusiones definitivas que permitan atribuirla a otro ingenio (Andrés de Claramonte es el candidato alternativo) y quitársela a la nómina tirsiana»; en cuanto a la prioridad del Burlador sobre Tan largo remito a los puntuales estudios ecdóticos de D'Agostino (2007 y 2009).

${ }^{4}$ Ver, por ejemplo, Arellano, «Introducción», en Burlador (Tirso, 1997: 59).

${ }^{5}$ Melloni (1981: 488), comentando la presencia de varios versos sueltos, subraya: «Come si sa grazie a una serie di studi, i sueltos abbondano nel teatro del Seicento fino alla prima decade del secolo, per poi diminuire fino a scomparire quasi totalmente dopo il 1620. Giacché la Zayas come autrice di novelas cortesanas e dell'unica commedia che conosciamo non sembra mettere in atto meccanismi trasgressori rispetto agli schemi compositivi dominanti, non parrebbe allora particolarmente azzardato fissare la data della TraiAm non lontano dal periodo 1610-1615». 
embargo, Paun de García, poniendo en tela de juicio la datación de la investigadora italiana con argumentos que no parecen descaminados, se inclina a indicar el periodo 1630-1635 como el más probable ${ }^{6}$. Las Novelas amorosas y ejemplares se remontan de forma aproximada a este mismo lapso temporal, mientras los Desengaños son algo posteriores.

Aunque se podría objetar que el mito del don Juan preexiste al Burlador, es decir que todos los elementos de la narración estaban allí antes de que su genial autor los reuniera en la misma obra $^{7}$, como vamos a ver La traición en la amistad y algunos relatos zayescos no se limitan a participar de una genérica interdiscursividad literaria, sino que entablan una relación paródica puntual justamente con el $U r$-don Juan, resultando un precioso testigo literario del éxito coetáneo del subtexto teatral y de su recepción por parte del público femenino. En este sentido la pieza de Zayas realiza una operación análoga a la que Calderón lleva a cabo en $\mathrm{No}$ hay cosa como callar ${ }^{8}$ y en $\mathrm{No}$ hay burlas con el amor (1987) ${ }^{9}$.

Algunos críticos se han percatado, a grandes rasgos, de este juego intertextual. Ximénez se ha limitado a hacer hincapié en la intención de la autora de «censurar los excesos de libertinaje, egoísmo, crueldad o petulancia de los galanes donjuanescos de la época» ${ }^{10}$. Larson, partiendo de algunas fugaces afirmaciones de Stroud y Hegstrom Oakey, dedica un breve artículo a la intertextualidad que vincula La traición al Burlador, aseverando que «We might

${ }^{6}$ Paun de García (1988: 377-379).

${ }^{7}$ Entre otros, Molho (1993: XI), sin mostrar especial interés por la problemática de la autoría del Ur-Burlador, destaca que «los orígenes míticos de Don Juan son indiscernibles pero, en todo caso, DJ preexiste a DJ1»; Lasaga Medina (2004: 56) también subraya que cuando se compuso el Burlador «el tema y el personaje estaban en el ambiente».

${ }^{8}$ Cfr. Costales (2009: 109 y 125): «Calderón se enfrenta con la ya creciente popularidad de don Juan en su protagonista [...] a la vez que distorsiona esta imagen en un proceso que Harold Bloom denominaría "un acto de corrección creativa" en el que Calderón intenta "corregir" la obra tirsiana»; «Muy lejos de las proporciones míticas de su predecesor, Calderón presenta a un hombre cualquiera que sucumbe a la justicia femenina, un don Juan domesticado, casado con Leonor».

${ }^{9}$ Son muchos los elementos del Burlador que se incrustan en un texto que, de hecho, presenta una dimensión metateatral especialmente desarrollada, con alusiones a varias comedias lopescas (La dama boba, Los melindres de Belisa y El caballero de Olmedo); si bien aparece un don Juan, el tipo donjuanesco es don Alonso, cuya inconstancia amorosa halla en su criado un riguroso cronista; ya en la secuencia de apertura Moscatel le echa en cara: «Como tú nunca has sabido / qué es estar enamorado / [...] fueron tus placeres / burlarte de las mujeres / y reírte de los hombres» (496); en la II jornada, el mismo le avisa de que Celia se queja de que no vaya a verla, y el protagonista contesta tal como esperaríamos del Tenorio: «[...] todas imaginan, / siendo galán al quitar, / que lo he de ser de por vida» (510), y más tarde cuando el amigo don Juan le pide que le haga tercio enamorando a Beatriz, exclama: « ¿Yo parlar a una ventana, / dos horas de noche fría, / para pedir una mano / a quien siempre que la pida / me responda, «es de mi esposo» / [...]?» (511); para más detalles remito a un trabajo en preparación.

${ }^{10}$ Ximénez de Sandoval (1949: 1481). 
say that Zayas play is simultaneously an inversion, a subversion, and a comic copy of the Burlador $\gg{ }^{11}$. No obstante, la investigadora anglosajona, más interesada en la interpretación ideológica de corte feminista que en los aspectos literarios, sólo destaca algunas macroscópicas analogías entre las dos comedias, pasando por alto numerosos ecos puntuales que conforman la reescritura dramática zayesca. Las páginas que siguen pretenden enriquecer el análisis del diálogo intertextual mediante el cual la autora madrileña nos depara un macrotexto literario antidonjuanesco muy acertado y original ${ }^{12}$.

De entrada, es preciso apuntar que las dramatis personae de La traición cuentan con tres personajes moldeados sobre el patrón del Tenorio: Liseo, Fenisa y, en menor medida, don Juan; los dos primeros son auténticos amadores seriales que van coleccionando víctimas de su poder seductor, si bien se connotan de forma muy distinta.

El galán, tras haber gozado a Laura bajo promesa de matrimonio, se ha hartado de ella y ha pasado a galantear a Marcia; pero cuando la desenvuelta Fenisa se le ofrece como amante no se lo piensa dos veces y aprovecha la ocasión ${ }^{13}$. El criado León así sintetiza su enredada situación sentimental: «Marcia, te adora y estima; / Fenisa, por ti muriendo. / ¿Y Laura?» (1994: 71, vv. 524-526).

El proceder de Liseo con las mujeres es exactamente el del burlador. Lo revela al público en la jornada de apertura Laura, primera víctima de sus hazañas eróticas que Larson asimila oportunamente a Tisbea ${ }^{14}$. La dama recuerda que fue «requebrada y pretendida», y que cedió a sus presiones porque le dio «palabra de esposo», pero después de su entrega todo ha cambiado: «Amante y tierno le vi / cuando ahora desdeñoso, / pues no se acuerda de mí» (81-82, vv. 750 ss.). Como es sabido don Juan Tenorio no conserva memoria de sus víctimas.

${ }^{11}$ Larson (1994-1995: 130); ver también en la misma página y más adelante: «Don Juan’s legacy is evident in the text and subtext of La traición en la amistad [...] In its treatment of the interaction of the sexes, Zayas's Traición both echoes and challenges Tirso's Burlador»; «Within the very structure of the Burlador, Tirso has blurred the lines separating victimizer and victim, subject and object, burlador and burlada. And this may well represent the closest point of contact between Zayas's and Tirso's dramas» (135).

${ }^{12}$ Tengo que confesar que, cuando redacté la primera versión de este ensayo, desconocía el artículo de Larson; cuando lo leí a posteriori, pude constatar que anticipaba sólo en mínima parte mi propia contribución, y decidí que merecía la pena dar a conocer mi estudio pormenorizado de la intertextualidad que con sus transformaciones irónicas vincula la comedia de Zayas al Burlador.

${ }^{13}$ Con respecto a este personaje, Larson (1994-1995: 129) se limita a observar: «The libidinous Liseo of Zayas's comedy sounds much like the infamous Don Juan Tenorio when he describes his plans for seduction»; en efecto, a la estudiosa anglosajona le interesa sobre todo la caracterización de Fenisa.

${ }^{14}$ Larson (1994-1995: 134): «Both Zayas's Laura and Tirso's Tisbea suffer after being rejected by their lovers, and both follow the men who have abandoned them, hoping to get them to honor their spoken commitment». 
También con las demás amantes la actitud de Liseo es falsa y engañosa. Cuando decide aprovechar el ofrecimiento amoroso de Fenisa, así se descarga la conciencia dirigiendo su pensamiento a la amiga de ésta:

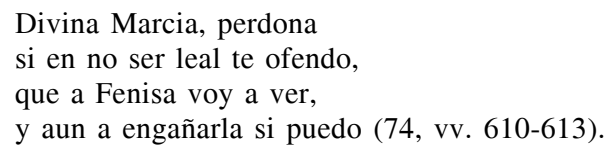

En una secuencia de la II jornada, hablando con su servidor, remacha la idea, confesando, sin rodeos, su naturaleza doble y mezquina: «León, si yo a Fenisa galanteo, / es con engaño, burlas y mentira, / no más de por cumplir con mi deseo» (103, vv. 1298-1300).

Al final Liseo se verá obligado a reconocer que su fracaso sentimental ha sido provocado por su actuación como burlador de mujeres:

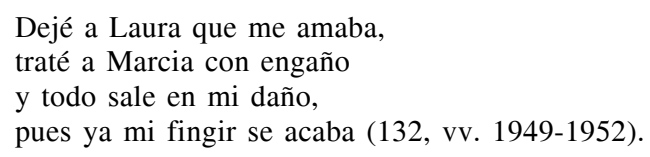

En una de las últimas secuencias dramáticas, Belisa, hablando con León, se encarga de lanzar la acusación al género masculino, generalizando el comportamiento de Liseo: «[...] los hombres tienen cien mujeres / sin querer a ninguna» (156, vv. 2517-2518).

Al igual que Catalinón, frente a los excesos de su amo, León mantiene una actitud ambivalente. Por un lado, cuando aquel reivindica su presunto recato, se mofa de él diciendo «Casto dice y tiene tres» (72, v. 554), y contando la anécdota burlesca de su abuelo cura que tuvo un sinnúmero de hijos ilegítimos por su incontinencia sexual. En la II jornada, el criado vuelve a ridiculizar la promiscuidad y serialidad amatorias de Liseo: « $¡$ Bueno eres para turco! ¡Linda vida, / si con media docena te casaras!» (102, vv. 1287-1288). Con razón, Teresa Ferrer destaca que María de Zayas hace del gracioso el vehículo de sus instancias pro feminam:

Así, el criado nos induce a compadecer a Laura, la dama engañada y abandonada, y de paso a considerar culpable a su señor por su carácter mudable, volviendo una vez más en contra de los hombres una acusación tradicionalmente utilizada en contra de las mujeres (Ferrer Valls, 2005: 307).

Pero, por otro lado, León le sigue la corriente a Liseo, conforme a su papel de fiel servidor. En el I acto, invita a su amo a ser un calavera porque es éste el tipo masculino que las damas prefieren:

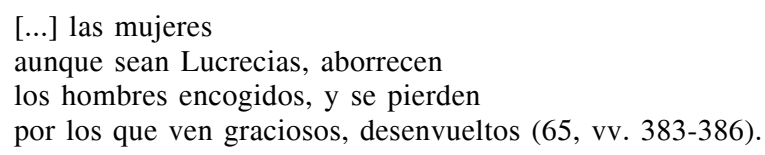


En clave metateatral, dicho comentario del criado sirve evidentemente para aleccionar al público femenino, señalándole su talón de Aquiles.

Cuando en la jornada III Liseo le cuenta abatido que Marcia, tras haberse enterado de su relación con Fenisa, lo aborrece, León lo incita a seguir con su vida disipada:

\author{
Calla, que eres mentecato, \\ dime ¿dónde está tu brío? \\ Hay mil mozas en la corte, \\ entre quince y veinte y cinco, \\ que sólo porque las quieras \\ te traerán siempre en palmitos (141, vv. 2182-2187).
}

Observemos de paso que en esta réplica del gracioso se esboza un catálogo potencial de mujeres conquistadas.

Así y todo, Zayas para desvirtuar el paradigma donjuanesco no se contenta con ridiculizar en la figura de Liseo al tipo dramático correspondiente, sino que decide duplicarlo, elaborando un paradójico don Juan mujer. Fenisa, con su práctica amatoria y su visión del amor, supera con creces a Liseo, el cual, en la economía de la comedia, acaba siendo una mera contrafigura de la dama, según apuntan certeramente los modernos editores de la pieza ${ }^{15}$.

Destaquemos de soslayo que la idea de llevar a las tablas una versión femenina del Tenorio no es exclusiva de Zayas, puesto que Tirso ya lo había hecho en Quien no cae no se levanta (2003); con todo, el perfil donjuanesco de la protagonista, Margarita, más que representado queda apenas esbozado ${ }^{16}$, y el tratamiento del tema es tan serio como en El burlador, conforme a la intencionalidad del dramaturgo de presentar el caso de una mujer pecadora que

\footnotetext{
15 González Santamera y Doménech. «Introducción», en Zayas (1994: 29).

${ }^{16}$ Al principio de la comedia, el viejo padre, Cleandro, se queja de la excesiva libertad y soltura de la hija que lleva una «mocedad libre y loca» (v. 57); en la II jornada, hablando con la criada Leonela, aboga por la variedad amorosa: «sabré a que sabe un casado / pues ya sé lo que es soltero» (vv. 1390-1391), y justo antes de escuchar la voz sobrenatural que más tarde la inducirá a arrepentirse, admite: «Sola estoy y no soy santa; / perdone mi padre viejo / que no hay gusto con consejo» (vv. 1400-1402); a continuación, cuando Lelio y Valerio se pelean por su amor y el segundo resulta herido, comenta Britón: «Aqueste vuestro amor es el dimuño. / Matáis a uno y engañáis a ciento» (vv. 1702-1703); a propósito de esta obra, Dolfi (2000), en las huellas de Lloyd, aísla las afinidades entre Margarita y don Juan, asentando que se trata «de una mujer que, como nuestro caballero, no se preocupa de la moral y se dedica a un genérico libertinaje del que no piensa retroceder a pesar de los reiterados reproches de su padre» (54); «Como en El burlador, Tirso se concentra aquí sobre un único protagonista (Margarita), sobre sus aventuras clandestinas, sus diferentes amantes, su rechazo del matrimonio, su irritación e indiferencia hacia las advertencias» (55); «En ambas comedias, pues, la intervención divina deberá renovarse: con un segundo convite para don Juan, con una segunda aparición para la mujer pecadora. Pero esta vez Tirso quiere representar ante su espectador, no un ejemplo negativo (la condena del culpable impenitente), sino un ejemplo positivo de la misma historia (la rendición del pecador)» (56).
} 
acaba arrepintiéndose. Nada que ver con la jocosa elaboración zayesca, la cual se enmarca más bien en una praxis de escritura en que:

Utilizando tópicos literarios, sirviéndose de escenarios canonizados, recurriendo al lenguaje del símbolo, María de Zayas pretende provocar una toma de conciencia en el público femenino, aleccionándole sobre una situación social injusta, e incitándole a volver por sus propios fueros, de ahí que tanto por la intencionalidad de la obra, como por la utilización sutilmente desviada de los tópicos, la producción de María de Zayas se inscriba, a pesar de las apariencias, dentro de la literatura de denuncia social, literatura comprometida, polémica y subversiva, en donde [...] los papeles sociales se invierten y las situaciones se revuelven (Ruiz Gálvez, 1998: 199).

Bueno, pues, desde sus primeras intervenciones Fenisa se define como una amante hiperbólica ${ }^{17}$. Después de haberse enamorado a primera vista de Liseo, comunica al público en aparte:

Aunque a don Juan digo amores

el alma en Liseo está,

que en ella posada habrá

para un millón de amadores (56, vv. 189-192).

Numerosos son los fragmentos del texto teatral en que la dama reitera esta misma idea, destinada a convertirse en el leitmotif que la connota como personaje. Aún en la I jornada remacha:

y aunque a mi don Juan adoro

quiero también a Liseo

porque en mi alma hay lugar

para amar a cuantos veo (67, vv. 432-435).

En un soneto de la II jornada, en que se dirige idealmente a Cupido, reconoce: «muchos amantes en mi alma caben», para luego afirmar su personal filosofía amatoria: «Mal haya la que sólo un hombre quiere, / que tener uno solo es cobardía» (111, vv. 1464, 1474-1475). Hablando a continuación con su criada Lucía, vuelve a hacer hincapié en el gran número de hombres que se hallan a sus pies: «Diez amantes me adoran, y yo a todos / los adoro, los quiero, los estimo, / y todos juntos en mi alma caben» (113, vv. 1518-1520).

Además, en su discurso se incrusta un verdadero catálogo de conquistas, pensado irónicamente desde el punto de vista femenino:

${ }^{17}$ Cfr. Larson (1994-1995: 130): «Fenisa echoes many of Don Juan's actions with regard to the opposite sex, claiming to have as many as ten lovers»; «Fenisa's strongest link to Don Juan [...] is her manipulation of the opposite sex in order to satisfy her own desires [...] Because her actions are controlled by desire and because she tramples on her friends for her own selfish ends, Fenisa resembles Tirso's Don Juan, the social rebel who leaves behind a trail of women and betrays his male friends for the sake of his own ego» (131). 


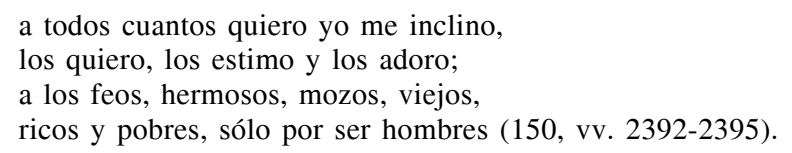

A este propósito, cabe notar que, si bien El burlador de Sevilla no presenta de forma explícita el motivo del catálogo, destinado a convertirse en un elemento constante y virtuosistico de las futuras elaboraciones teatrales del mito donjuanesco, alcanzando su más acabada realización en la lista del Don Giovanni de Mozart-Da Ponte, el mismo lo encontramos bien desarrollado ya en el teatro de Lope de Vega que tanto contribuye a forjar el mundo dramático y poético en el cual surge el primer don Juan ${ }^{18}$. Por lo visto, Zayas tiene la sensibilidad de comprender que se trata de un aspecto imprescindible de este mito literario.

Dos elementos donjuanescos ulteriores que atañen a la connotación de Fenisa son el olvido de los antiguos amantes y la traición de la amistad, tema central de la comedia. Al primero alude la propia dama en el momento en que, viendo el retrato, se enamora de Liseo y enseguida se siente desapegada de los demás caballeros: «¿Cuidado de tantos días / como el del galán Gerardo / por el que hoy empieza olvidas?» (53, vv. 126-128). El segundo, es decir el hecho de que Fenisa se entregue al enamorado de su mejor amiga, parodia el episodio del Burlador en que don Juan engaña al Marqués de la Mota para gozar en su lugar a doña Ana, prima y amante secreta de aquel. Me parece necesario subrayar con fuerza este aspecto porque es el pivote alrededor del cual gira toda la reescritura teatral zayesca.

Observemos que Lucía pone en solfa el carácter donjuanesco de la dama recurriendo a un argumento anecdótico parecido al que León había utilizado para mofarse de Liseo; la autora obtiene así un logrado paralelismo burlesco. Puesto que Fenisa insiste en que los amantes han de ser muchos, la criada echa mano de la opinión de su abuela: «Así decía mi agüela, que Dios haya, / que había[n] de ser en número infinito» (113, vv. 1508-1509). Al mismo tiempo, y análogamente a lo que hacen León y Catalinón, lanza avisos a su dueña, de acuerdo con el contexto cómico de la pieza.

Cuando en el cierre de la obra Fenisa se queda sola, no consigue comprender las razones de su fracaso y sigue reiterando su hiperbólica concepción del amor: «[...] a todos quiero, Lucía, / a todos juntos quería», hasta llegar a un frenesí que hace de ella un carácter desaforado y, en último análisis, ridículo ${ }^{19}$ :

${ }^{18}$ Remito a mi monografía en preparación El mito donjuanesco en el universo poético y teatral de Lope de Vega; entre las comedias del Fénix que deparan ejemplos de catálogos de mujeres se hallan La serrana de Tormes, La bella malmaridada, Los ramilletes de Madrid y Las bizarrías de Belisa.

${ }_{19}$ Melloni (1981: 490) cree que Fenisa desempeña el papel de segunda dama: «In una possibile gerarchia dei personaggi, Fenisa, che si trova investita del maggior potere e fino a 


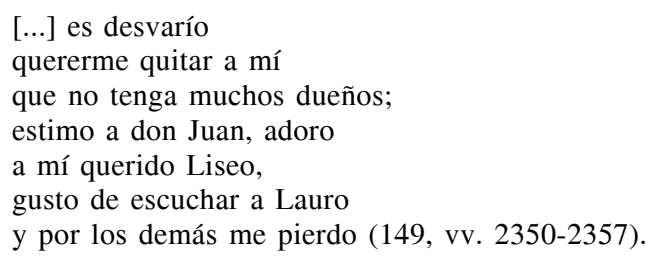

Desesperada por el progresivo abandono de todos los hombres que había seducido, la dama intenta recuperar en balde el amor de uno de ellos, pronunciando la fatídica frase de la seducción engañosa: «Dame la mano, don Juan», «Acaba, dame tu mano» (170, vv. 2861 y 2868).

No deja de ser emblemático que el nombre de este antiguo amante coincida con el del Burlador, ya que se trata de una inversión paródica funcional a la desmitificación del tipo masculino correspondiente. En concreto, este don Juan había traicionado a su antigua amada Belisa dejándose fascinar por $\mathrm{Fe}$ nisa, adhiriendo por una temporada al patrón de su homónimo hispalense. Así la dama ofendida lo increpa en una secuencia de la II jornada:

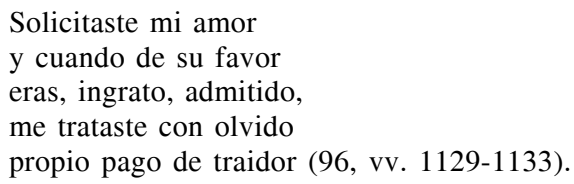

En efecto, como hemos recordado anteriormente, la falta de memoria con respecto a las pasadas conquistas es un motivo nuclear del Burlador. Pero don Juan ya se ha arrepentido y promete olvidar a la mujer que lo ha hecho descarrilar, ofreciendo a Belisa la mano de esposo con la tópica fórmula: «Dame de amiga la mano» (100, v. 1241). De manera paradójica, pues, este personaje, pese al nombre de pila, resulta ser el menos donjuanesco de los tres amantes engañosos del reparto.

Volviendo a Fenisa, adviértase que su donjuanismo es muy distinto al de Liseo. Si al galán, como queda dicho, le mueve la mera pulsión erótica, Fenisa hace alarde de su infinita capacidad de amar. De hecho, en la primera secuencia dramática el público asiste en directo a su enamoramiento de $\mathrm{Li}$ seo a través del retrato:

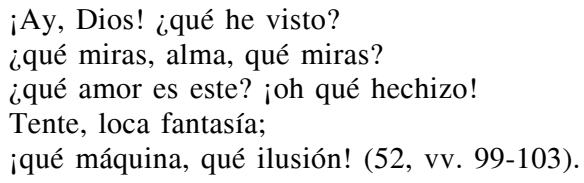

un certo punto manovra tutti gli altri, è senza dubbio la protagonista della commedia, ma nonostante che sia presentata come dama, amica di Marcia, il suo ruolo nell'economia dell'enredo è indubbiamente quello della seconda dama»; a mi modo de ver, este carácter se puede asimilar más bien a una «figurona», siendo, como es, una protagonista sui generis; sobre la versión femenina de este tipo risible, ver Gavela (2007). 
En segundo lugar, mientras Liseo traiciona con malicia a sus amantes, Fenisa, a su manera, es un personaje utópicamente convencido de que se pueda amar a muchos sin burlarse de nadie. A su criada asegura en una ocasión: «¿Qué cosa es engañar? Yo ya te he dicho / que a todos quiero y a ninguno engaño» (150, vv. 2386-2387). Pero es obvio que su punto de vista resulta inaceptable porque ignora los sentimientos ajenos. Lucía intenta explicárselo, cuando su ama se queja del olvido de sus antiguos amantes:

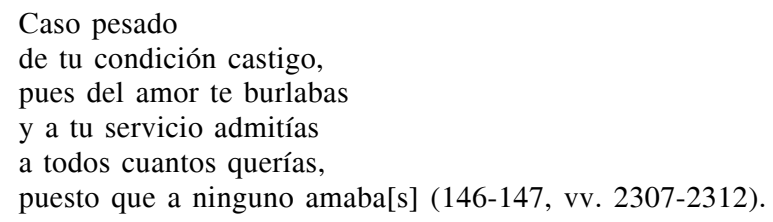

Más tarde, rompiendo la ilusión dramática, la criada se dirige directamente al público femenino para cuestionar el comportamiento de Fenisa:

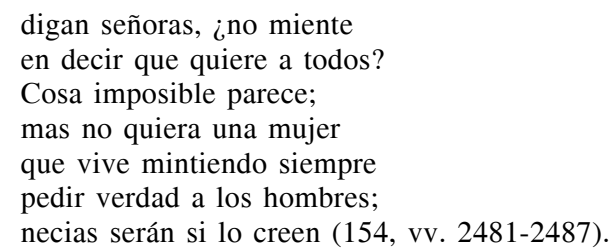

Diríase que dicha moraleja revela el sentido que para Zayas adquiere la conformación de su don Juan femenino: la denuncia de los engaños masculinos no puede evidentemente implicar la justificación de los mismos excesos por parte de las mujeres. Pero, con todo, una dama nunca puede alcanzar las vetas de maldad y bajeza de un burlador varón, por muy hiperbólico que sea su donjuanismo. En definitiva, el de Fenisa es un personaje censurable no tanto por su desenvoltura erótica ${ }^{20}$, sino porque traiciona la amistad de Marcia. El rótulo de la comedia nos lo confirma sin $\operatorname{rodeos}^{21}$.

${ }^{20}$ Fenisa pertenece, en este sentido, a esa categoría de mujeres libres, muy recurrente en las páginas de María de Zayas, que transgreden la imagen femenina tradicional; $c f r$. Prieto (2004: 1479): «El tipo de protagonista libre y desenvuelta que nos muestra Zayas es un desafío al estereotipo de la mujer pasiva y acallada por la honra»; Rodríguez Garrido (1997: 359): «las mujeres aparecen en la comedia libradas al ejercicio de su voluntad y de su ingenio, sin necesidad de recurrir al disfraz varonil, tan frecuente en la comedia de enredo cuando un personaje femenino traza la recuperación de su honor».

${ }^{21}$ Cfr. Ferrer Valls (1995: 101): «El principal defecto del personaje, y por el cual las otras mujeres la censuran enérgicamente, es más el de la deslealtad hacia sus amigas, a las que va robando los amantes uno a uno, que al de la falta de castidad»; Rodríguez Garrido (1997: 364): «Fenisa es marginada no tanto por su libertad amorosa, sino porque su proceder egoísta quiebra el ideal unitario y solidario en que se basa ese nuevo orden logrado a partir de la dirección de Marcia». 
Por último, quizás valga la pena destacar que Fenisa, al contrario de Liseo y demás galanes, seduce mediante la escritura más que por la palabra oral, ya que se ofrece al protagonista a través de una carta; dicho de otra manera, incluso su clase de seducción es más refinada que la masculina.

Hasta aquí hemos constatado en qué medida Fenisa, Liseo y don Juan quedan elaborados paródicamente a partir del modelo del Tenorio, pero se pueden recortar ecos intertextuales puntuales de otros aspectos del Burlador de Sevilla.

El más relevante lo encontramos en una secuencia dramática de la jornada III: Marcia y Laura se han puesto de acuerdo para vengarse del falso e inconstante Liseo, obligándole a pagar su deuda amorosa con su primera amante. Después de echarle en cara sus culpas, Laura, fingiendo ser Marcia, le da a entender que ya lo aborrece, y Marcia, simulando ser Belisa, en términos que podríamos definir metateatrales dictamina: «Bien dijo quien decía / “mal haya la mujer que en hombres fía"» (136, vv. 2066-2067)22. Ahora bien, en el acto III del Burlador de Sevilla emiten esta misma sentencia Tisbea e Isabela, en la secuencia en que las dos se encuentran, descubren ser ambas víctimas de don Juan, y toman la resolución de vengarse juntas. Como se ve, se trata de una situación análoga a la que elabora María de Zayas en su comedia. En el subtexto la muletilla se repite en cuatro versos, ya que tanto Tisbea como Isabela la pronuncian dos veces cada una, creando un efecto rítmico acelerado que parece anticipar los pasos inexorables de la estatua de piedra del Comendador que pronto va a ocupar el escenario.

Apuntemos que dicha maldición no parece pertenecer al corpus de frases proverbiales, pero sí es recurrente en el repertorio teatral tanto de Lope como de Tirso, en comedias que en mayor o menor medida están relacionadas con el tema donjuanesco ${ }^{23}$. En cualquier caso, enmarcándose en una operación paródica de gran envergadura, es patente que Zayas está haciendo dialogar su comedia justamente con el primer don Juan.

Aún hablando de muletillas, hace falta recordar que en el subtexto varios personajes repiten una frase que sintetiza su peculiar estado de ánimo; Tisbea utiliza tres: la que expresa los temores de la traición («iplega a Dios que no mintáis!»), la que apunta al estrago del abandono («iFuego, zagales, fuego, agua, agua! / ¡Amor, clemencia, que se abrasa el alma!»), y la que repite al final con Isabela, según acabamos de recordar. Laura, que parodia a Tis-

${ }^{22}$ Este aspecto ha sido apuntado de paso por Larson (1994-1995: 129): «In several guises, Tirso's words echo within Zayas's text; the classic examples are Marcia's complaint, «Bien dijo quien decía / mal haya la mujer que en hombres fía», and Fenisa's comic inversion: «Mal haya la que sólo un hombre quiere, / que tener uno solo es cobardía»».

${ }^{23} \mathrm{La}$ muletilla, a veces con alguna variante, se incrusta respectivamente en La esclava de su galán, ¡Ay, verdades, que en amor...! y Las bizarrías de Belisa de Lope; en Segunda parte de Santa Juana, La villana de Vallecas de Tirso y Los amantes de Teruel, también atribuida al mercedario. 
bea y anticipa a las futuras Elviras de afortunadas versiones del mito, tiene su propia muletilla que se reitera dos veces: «¡Piadoso cielo, duélete de mí, / que amando, aborrecida muero al fin!» (84, vv. 827-828, 847-848).

Pese a que La traición es una pieza cómica, también el segundo núcleo temático del Burlador, es decir el que se halla relacionado con la muerte de don Gonzalo y con la trascendencia, ofrece a Zayas pretextos para intrigantes inversiones.

Ante todo, el duelo entre el Tenorio y el Comendador en la comedia de doña María se convierte en la afrenta que don Juan hace a Fenisa para vengarse de sus engaños. En una secuencia dramática del acto intermedio, el galán, ya arrepentido y de nuevo enamorado de Belisa, da cuenta a la misma de cómo, estando a punto de darle con la daga a la pérfida dama, se detuvo para que no le echasen la culpa a ella. Así Belisa comenta el lance:

Bien hiciste, que es crueldad;

y a las mujeres de prendas

les basta para castigo

no hacer don Juan, caso de ellas (122, vv. 1740-1743).

De esta manera, el motivo del combate registra aquí un trueque de papeles, siendo la víctima de la ofensa uno de los personajes donjuanescos.

Otra inversión irónica, que nos desplaza del nivel trascendente a la dimensión material de la comedia, es el que atañe al elemento de la piedra: en efecto, aquí, en lugar de aludir a la estatua del Comendador, simboliza la frialdad del hombre traidor. En la secuencia del acto I en que Laura da cuenta a su paje Félix de su deshonra, este último se refiere a Liseo usando la perífrasis «aquel corazón de piedra», y la propia dama desdichada admite que el galán es «dura piedra para mí» $(83$, vv. 817 y 824$)$.

También el episodio del desafío al muerto sufre una maliciosa deformación paródica. Sabido es que ante la tumba del Comendador, don Juan muestra falta de respeto a la memoria de su víctima, mesándole las barbas: «¿Y habéisos vos de vengar, / buen viejo, barbas de piedra?»; por su parte Catalinón comenta: «No se las podrás pelar; / que en barbas muy fuertes medra» (169-170, vv. 2280-2283). Pues bien, en una secuencia de la II jornada de $L a$ traición, Fenisa encara al gracioso León, furiosa porque éste acaba de entregar a su amo una carta de Laura, y el criado se defiende diciendo: «¿En qué te ofenden mis barbas / que así a mesarlas te atreves? / ¿He de pagar yo tu rabia?» (105, vv. 1346-1348). En la inversión se modifican radicalmente la clase y la víctima del enfrentamiento, pero la alusión a las barbas funciona como elemento irónico que pone en relación el hipertexto con el subtexto.

En cuanto al castigo final del burlador, la comedia de Zayas multiplica las alusiones en un juego de espejos paródicos muy sutil, que involucra a los tres caracteres relacionados con el tipo paradigmático. Recordemos que en el cierre del Burlador, cuando se difunde la noticia de la muerte de don Juan, el rey comenta: «jJusto castigo del cielo!» (193, v. 2883). 
Así, pues, aunque la punición de Liseo va a cargo de las mujeres que ha engañado, en un fragmento el paje de Laura, intentando consolar a la dama, invoca el castigo divino: «Queda en buen hora, que el cielo / cansado ya de sufrir / te vengará deste ingrato» (84, vv. 843-845).

Por lo que respecta a Fenisa, es Lucía quien se encarga de escarmentarla jocosamente: «También en el infierno hay muchas sillas / y las ocupan más que no en el cielo» (150-151, vv. 2399-2400).

Finalmente, don Juan, contrito ante Belisa, asegura que estaría dispuesto a padecer el castigo que le toca realmente a algunos homónimos; pensemos en el canovaccio de la Commedia dell'Arte titulado L'ateista fulminato:

Si a Fenisa no aborrezco,

aquí se acabe mi vida,

aquí me destruya un rayo,

aquí el cielo me persiga... (100, vv. 1233-1236).

Para terminar con el análisis de La traición, cabe señalar la presencia en el tejido poético de la comedia de un verbo peculiar que se engasta también en el texto del Burlador y que, por lo mismo, podría ser un índice ulterior de la parodia realizada por la autora. Se trata de «amartelar», italianismo que significa «dar celos» o «enamorar, solicitar y acariciar a alguna persona, particularmente mujer» (Aut.). De hecho es un vocablo que pertenece al idiolecto poético de Lope de Vega, llegando casi a ser una marca estilística suya, y que, específicamente en el teatro, se halla en escasos autores, fuera de su repertorio $^{24}$. Para lo que aquí importa, en el acto III del Burlador don Diego sugiere al Rey de Castilla que case a doña Ana con el marqués de la Mota para restaurar su honra: «Fácil será al marqués el persuadille; / que de su prima amartelado estaba» (180, vv. 2549-2550). En la comedia zayesca, el verbo se utiliza en dos fragmentos ambos a cargo de la protagonista. En el mencionado soneto a Cupido, Fenisa auspicia: «mi nuevo amartelar todos alaben» (111, v. 1465), aludiendo a su repentina pasión amorosa por Liseo. Más adelante, intentando seducir en balde a Gerardo, que permanece fiel a Marcia, le persigue diciendo: «¡Oyeme, señor, y vuelve, / que con aquesas injurias / amartelada me tienes!» (115, vv. 1584-1586).

$\mathrm{Si}$ es cierto que el tratamiento del tema donjuanesco que Zayas reserva en la pieza se armoniza con el código dramático de la comedia cómica, en sus novelas el mismo queda elaborado con un tono serio y, en ocasiones, hasta trágico.

${ }^{24}$ El repertorio del TESO revela que, fuera del corpus lopesco, donde abunda, el verbo «amartelar» se emplea en algunas comedias de los discípulos más directos del Fénix, es decir, Tirso (Averíguelo Vargas y La mujer por fuerza), y Pérez de Montalbán (Los templarios y La ganancia por la mano), además de engastarse en La cautela en la amistad de Moreto, asimismo muy deudor de la escritura lopesca; por otra parte, una búsqueda estadística en el CORDE de la R.A.E. nos proporciona ejemplos de otros autores en textos no dramáticos, todos fechados entre finales del siglo XVI y principios del XVII. 
Empecemos por notar que en el marco narrativo de las Novelas amorosas Lisis resulta humillada por un don Juan que prefiere a su prima Lisarda, y que en la introducción de la Noche IV, la dama engasta en su canto melancólico una maldición análoga a la muletilla recordada de Tisbea e Isabela:

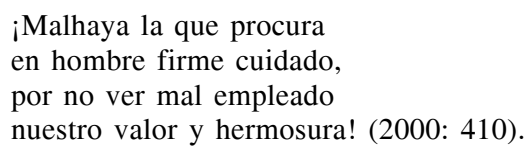

En la quinta «maravilla» del mismo libro, Laura, desesperada porque su esposo la traiciona con su amante Nise, pronuncia a su vez una frase muy parecida, aún referida a la mudanza de los hombres: «¡Mal haya la mujer que en ellos cree...!»(364).

Pero sobre todo dos novelas de esta colección presentan un entramado textual plagado de ecos del Ur-don Juan. En La burlada Aminta y venganza del honor, segunda «maravilla» cuyo título es ya de por sí emblemático, Francisco deja a su esposa en Madrid para vivir con su amante Flora y, al mismo tiempo, ocultando su identidad bajo el falso nombre de Jacinto, enamora y goza a la ingenua Aminta, abandonándola justo después de la posesión. Fijémonos en que el nombre de la joven coincide con el de la villana seducida por el Tenorio el día de sus bodas con Batricio.

Don Francisco, para conseguir la entrega amorosa, recurre a la técnica bien experimentada por su colega sevillano: «Le dio la mano de esposo»(226). Cuando más tarde, la protagonista se disfraza de hombre para servir en casa de su engañador, éste, observándola, comenta: «os parecéis a una persona que yo quise veinticuatro horas» (239), lo que corresponde, a todas luces, a la praxis amatoria del don Juan.

Aminta, por su parte, en un madrigal que canta en presencia del falso amante, además de incrustar en los versos otro nombre femenino del reparto del Burlador, «Isbella», esboza con lograda síntesis al tipo del varón traicionero en acción:

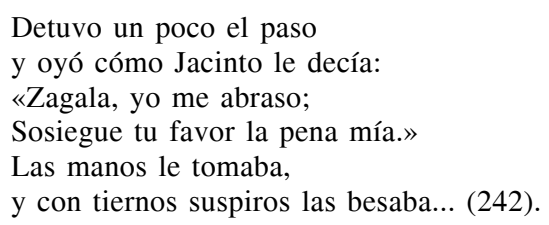

Adviértase que en el cierre de la novela se produce la muerte del embaucador con una solución humana del tema del castigo.

En la sexta «maravilla» una doña Juana es traicionada por un joven calavera, cuyo curriculum vitae no deja lugar a dudas: «[tuvo] lugar don Fernando de darse más sin rienda a sus vicios y travesuras, pendencias, juegos y damas» (374). Apuntemos que el nombre de la dama funciona como un índi- 
ce oblicuo de la operación paródica que la autora lleva a cabo en relación con el Burlador.

Juana no cede en seguida a las pretensiones del galán, consiguiendo encender su pasión: «La dama [...] para amartelarle más se hacía de temer, obligándole con desdenes a enamorarse más» (375). Según queda dicho, el recurso al verbo «amartelar» no parece inocente.

La narradora continúa explicando que don Fernando «si al principio empezó de burla, ya la quería de veras» (375), y que la seducción acaba produciéndose:

aunque don Fernando quería bien a doña Juana, no de suerte que se rematase ni dejase por su amistad las demás ocasiones que le venían a las manos (suerte de amante falso) [...] rindióse doña Juana, y no es maravilla, pues se vio obligar con la palabra que le dio de ser su esposo, oro con que los hombres disimulan la píldora amarga de sus engaños (379).

Como siempre suele pasar con los falsos amantes, en breve a don Fernando «ya la posesión le daba enfado» (379), y termina traicionando a la protagonista con su amiga Lucrecia. Para recuperar su amor, Juana, desesperada, no sabe hallar otro remedio que recurrir a la magia, comportándose así de forma moralmente censurable. En este sentido, la protagonista peca al igual que su modelo teatral.

Más adelante, Octavio, un enamorado baldío cuyo nombre forma parte asimismo del reparto del Burlador, aparece a Juana como fantasma cargado de cadenas para darle un aviso con ecos paródicos del primer don Juan:

Cánsate ya de la mala vida en que estás, teme a Dios y la cuenta que le has de dar de tus pecados y destraimientos [...] Teme, que te dijo que estás en los infiernos, dale gracias porque te avisa enternecido de tu perdición [...] Y mira por tu alma, que es lo que te importa, que una vez perdida no hay otra pérdida mayor ni ganancia que supla su falta (387).

De acuerdo con la intencionalidad paródica de la autora, doña Juana, al contrario del Tenorio, se arrepiente e ingresa en un convento.

Tras lo cual, don Fernando se casa con doña Clara, y pronto vuelve a su relación clandestina con Lucrecia, yéndose con ella a Sevilla, patria del Burlador.

Su esposa, siendo una mujer virtuosa, aun hallándose en estrecheces económicas, rechaza la ayuda de don Sancho: «No hay deudas [...] que mejor se paguen que las de la voluntad» (396). Estas palabras son un eco puntual de la lúgubre canción que acompaña la aparición del convidado de piedra en el último acto del Burlador: «[...] no hay plazo que no llegue / ni deuda que no se pague» (188, vv. 2758-2759). Por otra parte, de forma análoga al modelo de Tisbea y Laura, Clara persigue al marido inconstante, y en una ocasión canta unas coplas sobre el motivo del «fugitivo pajarillo», símbolo del «ga- 
lán mujeriego, lisonjero, engañoso y traidor», tal como anota Olivares ${ }^{25}$. Al final, don Fernando padecerá el justo castigo, muriéndose por los hechizos de su amante.

También en la segunda colección zayesca se hallan motivos y situaciones que remiten claramente al patrón literario que tanto le intriga a la autora. Por ejemplo, en El verdugo de su esposa, tercero de los Desengaños amorosos, un don Juan quiere conquistar a la mujer de su mejor amigo, motivo que, como hemos subrayado, resulta central ya en La traición en la amistad, en tanto en cuanto parodia de un episodio nuclear del subtexto dramático.

La narradora del «desengaño noveno», doña Estefanía, así arenga a las damas que la escuchan: «el día de hoy el mayor honor y la mayor hazaña de que se precian los hombres es de burlaros y luego publicarlo y decir mal de vosotras» (1993: 458), palabras que evocan la réplica de don Juan solo en el escenario saboreando el momento en qué irá a seducir a doña Ana:

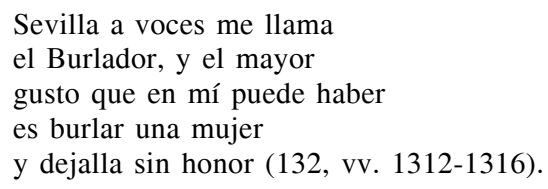

Se podrían seguir citando ejemplos análogos que, de hecho, no añadirían nada fundamental a lo subrayado en las páginas anteriores. Así, pues, a la luz de lo expuesto, no cabe duda de que La traición en la amistad y las novelas zayescas se construyen, entre otras cosas, a partir de un subtexto específico que es El burlador de Sevilla, porque en el repertorio literario coetáneo ésta es la obra en que se cristaliza magistralmente el paradigma de ese comportamiento masculino irrespetuoso para con las mujeres que la escritora madrileña se empeña en censurar a lo largo y a lo ancho de su producción. Eligiendo el subgénero de la comedia de capa y espada, Zayas elabora su anti-don Juan teatral en clave festiva, pero sin olvidar nunca la dimensión ética que lo vertebra, permaneciendo fiel al ideal del utile dulci que también impregna su escritura novelística. Diríase que la autora madrileña conoce al dedillo el texto del Burlador, que probablemente poseía en alguna edición impresa, y da muestras de ser muy ingeniosa en la construcción de los juegos paródicos que enriquecen sus obras.

Para concluir diríase que María de Zayas depara al público del seiscientos un anti-don Juan parecido al que Ventura de la Vega realizará en el siglo XIX con su comedia de salón El hombre de mundo, parodiando el Don Juan Tenorio de Zorrilla ${ }^{26}$. Con todo, sólo en la prosa su escritura «feminizada»

\footnotetext{
${ }^{25}$ En Zayas (2000: 394, n. a).

${ }^{26}$ Cfr. Dowling (1980: 215): «Los dos estrenos [del Tenorio y del Hombre de mundo] representan, con matices curiosos e interesantes, el careo de dos actores y de dos teatros, de dos estilos teatrales, de dos corrientes dramáticas, y de dos morales»; Yáñez (1998: 157):
} 
(Alcalde, 2005) logra ser innovativa y transgresiva tanto a nivel estético como ideológico. Desde el punto de vista dramático, La traición en la amistad respeta, en efecto, los cánones del subtipo de la comedia cómica, terminando con una serie de matrimonios entre Marcia y Gerardo, Liseo y Laura, don Juan y Belisa. Que Fenisa acabe sin pareja al final de la acción no es de por sí un hecho original, ya que se dan casos de figuronas y damas sueltas en la comedia nueva. Al fin y al cabo, no se puede pasar por alto que en el teatro, siendo el dominio masculino por excelencia por su dimensión pública, una mujer de la España barroca difícilmente hubiera podido desafiar los cánones establecidos proponiendo una fórmula teatral realmente alternativa. A lo mejor tampoco era esto lo que pretendía la autora, siendo en cambio su intención prioritaria la de aleccionar a las mujeres para que aprendieran a esquivar a los hombres que se burlaban y abusaban de ellas, censurando el modelo de comportamiento masculino de mayor éxito teatral y social: el del don Juan.

\section{BIBLIOGRAFÍA CITADA}

Alcalde, Pilar (2005). Estrategias temáticas y narrativas en la novela feminizada de María de Zayas. Newark, Delaware: Juan de la Cuesta.

Calderón de la Barca, Pedro (1987). No hay burlas con el amor, en Obras completas. Ángel Valbuena-Briones (ed.). Madrid: Aguilar.

Costales, Kathleen (2009). «Don Juan domesticado o la desmitificación del tipo en No hay cosa como callar de Calderón», Bulletin of the Comediantes, vol. 61, n. 1, pp. 109-128.

Cruickshank, Don (1981). «The first edition of El burlador de Sevilla», Hispanic Review, 49, pp. 443-467.

D'Agostino, Alfonso (2007). «Ocho apostillas al texto de «El burlador de Sevilla»», en Álvaro Alonso, J. Ignacio Díez Fernández (eds.), «Non omnis morier»: estudios en memoria de Jesús Sepúlveda, Analecta Malacitana (anejo 65). Málaga: Universidad de Málaga, pp. 259-276.

D'Agostino, Alfonso (2009). «Más apuntes sobre El burlador de Sevilla y Tan largo me lo fiáis», en Giuseppe Bellini (ed.), "En el mar veneciano, puerto cierto». Omaggio degli ispanoamericanisti milanesi a Donatella Ferro. Roma: Bulzoni, pp. 71-85.

Díez Borque, José M. ${ }^{a}$ (1979). «El feminismo de doña María de Zayas», en La mujer en el teatro y la novela del siglo XVII, Actas del II Coloquio del Grupo de Estudios sobre Teatro Español (G.E.S.T.E.), (Toulouse, 16-17 de noviembre de 1978). Toulouse: FranceIbérie Recherche, Université de Toulouse-Le Mirail, pp. 63-83.

Dolfi, Laura (2000). «El burlador burlado. Don Juan en el teatro de Tirso de Molina», en Ignacio Arellano Ayuso y Blanca Oteiza (eds.), Varia lección de Tirso de Molina, Actas del VIII Seminario del Centro para la edición de clásicos españoles (Madrid, 5-6 de julio de 1999). Pamplona: GRISO, pp. 31-63.

«Un año después de la aparición del Tenorio, Ventura de la Vega, unido generacionalmente a los románticos, había dado el primer paso hacia su ridiculización. Que El hombre de mundo es una teatralización del «anti-don Juan» nadie lo ha puesto en duda. Ya John Dowling empleó con fortuna este término en 1980. Lo que, a mi entender, todavía no se ha hecho, es constatar los diversos elementos donjuanescos del texto y los procedimientos irónicos de su transformación». 
Dowling, John (1980). «El anti-don Juan de Ventura de la Vega», en Alan M. Gordon y Evelyn Rugg (eds.), Actas del Sexto Congreso Internacional de Hispanistas. Toronto: University of Toronto, pp. 215-218.

Ferrer Valls, Teresa (1995). «La ruptura del silencio: mujeres dramaturgas en el Siglo XVII», en Mujeres: escrituras y lenguajes (en la cultura latinoamericana y española). Valencia: Universitat de València, pp. 92-108.

Ferrer Valls, Teresa (2005). «»Locuras y sinrazones son las verdades»: la figura del gracioso en las obras dramáticas escritas por mujeres», en Luciano García Lorenzo (ed.), $L a$ construcción de un personaje: el gracioso. Caracas, Madrid: Ed. Fundamentos, pp. 297316.

Foa, Sandra M. (1978). «María de Zayas: visión conflictiva y renuncia del mundo», Cuadernos Hispanoamericanos. 331, pp. 128-135.

Gavela, Delia (2007). «La evolución de un género a través de sus figuras y figurones: $D e$ fuera vendrá, de Moreto, y su fuente lopesca ¿De cuándo acá nos vino?», en Luciano García Lorenzo (ed.), El figurón. Texto y puesta en escena. Madrid: Ed. Fundamentos, pp. 129-147.

Larson, Catherine (1994-1995). «Gender, reading, and intertextuality: Don Juan's legacy in María de Zayas's La traición en la amistad», INTI: Revista de literatura hispánica. 4041 , pp. $129-138$.

Lasaga Medina, José. (2004). Las metamorfosis del seductor. Ensayo sobre el mito de don Juan. Madrid: Síntesis.

Melloni, Alessandra (1981). «María de Zayas fra comedia e novela», en Manuel Sito Alba (ed.), Actas del Coloquio Teoría y realidad en el teatro español del siglo XVII. La influencia italiana (Roma, 16-19 de noviembre de 1978). Roma: Instituto Español de Cultura y de Literatura de Roma, pp. 485-505.

Molho, Maurice (1993). Mitologías. Don Juan. Segismundo. Madrid: Siglo XXI editores.

Paun de García, Susan (1988). «»Traición en la amistad» de María de Zayas», Anales de Literatura Española. 6, pp. 377-390.

Prieto, Char (2004). «María de Zayas o la forja de la novela de autora en los albores del nuevo milenio», en María Luisa Lobato y Francisco Domínguez Matito (eds.), Memoria de la palabra. Actas del VI Congreso de la Asociación Internacional Siglo de Oro. Madrid, Frankfurt am Main: Iberoamericana, Vervuert, pp. 1477-1484.

Riera, Carme y Luisa Cotoner (1987). «Los personajes femeninos de doña María de Zayas, una aproximación», en Actas de las Cuartas Jornadas de investigación interdisciplinaria, Literatura y vida cotidiana. Zaragoza: Seminario de Estudios de la Mujer, Universidad Autónoma de Madrid, pp. 149-159.

Rodríguez Garrido, José A. (1997). «El ingenio en la mujer: La traición en la amistad de María de Zayas entre Lope de Vega y Huarte de San Juan», Bulletin of the Comediantes. 49, 2, pp. 357-373.

Ruiz Gálvez, Estrella (1998). «Tras la careta: imagen, disfraz e identidad en la obra de María de Zayas», en Bernard Fouques y Antonio Martínez González (eds.), Imágenes de mujeres. Image de femmes. Caen: Université de Caen, Laboratoire d'Études Italiennes, Ibériques et Ibéroamericaines, pp. 199-212.

Tirso de Molina (1997). El burlador de Sevilla. Ignacio Arellano (ed.). Madrid: Espasa.

Tirso de Molina (2003). Quien no cae no se levanta. [En línea, según la versión de Vern Williamsen, 2000]. David Hildner (ed.). www.comedias.org/tirso/QUIEN-NO-CAE.pdf [ref. de 2 de octubre de 2014].

Ximénez de Sandoval, Felipe (1949). Varias historias de mujeres ilustres. Madrid: Ediciones y Publicaciones Españolas.

Yáñez, María-Paz (1998). «»Lo que va de ayer (1844) a hoy (1845)»: del donjuanismo en El hombre de mundo de Ventura de la Vega», en Luis F. Díaz Larios y Enrique Miralles 
(eds.), Actas del I Coloquio Del Romanticismo al Realismo (Barcelona, 24-26 de octubre de 1996). Barcelona: Universitat de Barcelona, pp. 155-165.

Zayas, María de (1993). Desengaños amorosos. Alicia Yllera (ed.). Madrid: Cátedra.

Zayas, María de (1994). La traición en la amistad. Con Entreactos de la Tragicomedia de los Jardines y Campos Sabeos de Feliciana Enríquez de Guzmán y La firmeza en el ausencia de Leonor de la Cueva y Silva. Madrid: Asociación de Directores de Escena de España, pp. 45-172.

Zayas, María de (2000). Novelas amorosas y ejemplares, Julián Olivares (ed.). Madrid: Cátedra.

Fecha de recepción: 3 de mayo de 2012

Fecha de aceptación: 17 de diciembre de 2012 